\title{
Análisis multitemporal para la detección de cambios en el uso del suelo en tres municipios afectados por el huracán Juana
}

\author{
Marcos Williamson \\ Director CISA-URACCAN
}

Después de la magistral exposición de la máster Gladis Luna, la parte mía va a corresponder un poco a hacer el análisis de los cambios que se han venido dando en el uso del suelo en tres municipios que fueron afectados por el huracán Juana. Esto, básicamente, es un análisis en el cual utilizamos la tecnología de los sistemas de información geográficas, utilizando un método de clasificación cruzada, es decir, lo que hicimos fue tomar las diferentes capas de información de un año 1, un año 2 y un año 3. A esta capa de información que fue obtenida de los ministerios tanto INAFOR como al MARENA se le hicieron tres grandes grupos: una capa de información donde estaban los bosques, una capa de información donde estaban los humedales y una capa de información donde ya no hay bosque, pero que se convirtió en sistema agropecuario.

Para entender este modelo de matriz de cambio, uno tiene que ver la gráfica siguiente donde se toma la capa de información y se clasifica por año. Un ejemplo de lo que quiero decir es que si nosotros tenemos un área que tiene bosque latifoliado cerrado en el año uno, y tenemos que la siguiente capa de información del año dos tiene también la misma categoría, que es bosque latifoliado cerrado, a esto le vamos a denominar que presenta una condición estable. El segundo ejemplo es que si tenemos un bosque latifoliado cerrado en el año uno, y ésta en el año dos se vuelve un bosque latifoliado abierto, obviamente hay una pérdida de cobertura. En el caso tercero es, por ejemplo, si tenemos un sistema agropecuario en el año uno y éste se vuelve en un bosque latifoliado cerrado en el año dos, significa que hay ganancia. La lógica es que mientras haya mayor presencia de bosque existe ganancia, y cuando este bosque se está transformando, ya sea en un bosque latifoliado abierto o un manglar o a un sistema agropecuario, obviamente la transformación que existe es que este bosque está pasando a otro sistema de uso. El peor de los usos, obviamente, es que un bosque cerrado pase a un sistema agropecuario; es lo que se le denomina básicamente la frontera agrícola.

Entonces, repito, la lógica es que la cobertura vegetal de mayor o mejor expresión es un bosque. A medida que se vaya degradando ese bosque se puede convertir en un bosque latifoliado abierto, en un manglar, un humedal y hasta llegar a un sistema agropecuario. Esta es más o menos la dinámica. Y los colores que utilizamos son los de los semáforos: verde es ganancia; amarillo es estable, y perdida de bosque es rojo.

Bajo este modelo hicimos un análisis en los sitios por donde pasó el huracán Juana, y analizamos básicamente 22 poblaciones que fueron afectadas de los departamentos de Boaco, Chontales, Zelaya Sur, entre otras. Lo que se determinó fue que hubo una pérdida aproximada de 500 mil hectáreas de bosques dañados, y 100 mil hectáreas de humedales. Si hacemos comparación, esto es básicamente igual al impacto que acaba de ocurrir con el huracán Félix, en la RAAN.

\begin{tabular}{|l|l|l|l|l|l|}
\hline \multicolumn{6}{|c|}{ Modelo Matriz de cambio } \\
\hline & Blc & Bla & Man & Humedales & Agrop \\
\hline Blc & E & P & P & P & P \\
\hline Bla & G & E & P & P & P \\
\hline Man & G & G & E & P & P \\
\hline Humedales & G & G & G & E & P \\
\hline Agrop & G & G & G & G & E \\
\hline \multicolumn{5}{|l}{} \\
\hline \multicolumn{5}{|l}{} \\
& $\begin{array}{l}\text { Estable } \\
\text { Ganancia } \\
\text { Perdida }\end{array}$ \\
\hline
\end{tabular}


A continuación les muestro la trayectoria por donde pasó el huracán y el área en donde hicimos el análisis. Ustedes podrán ver la franja roja, que es por donde entró el huracán Juana y la categoría cinco es que estaba en categoría de huracán; después, cuando ya iba por Rama se convirtió en una tormenta tropical.

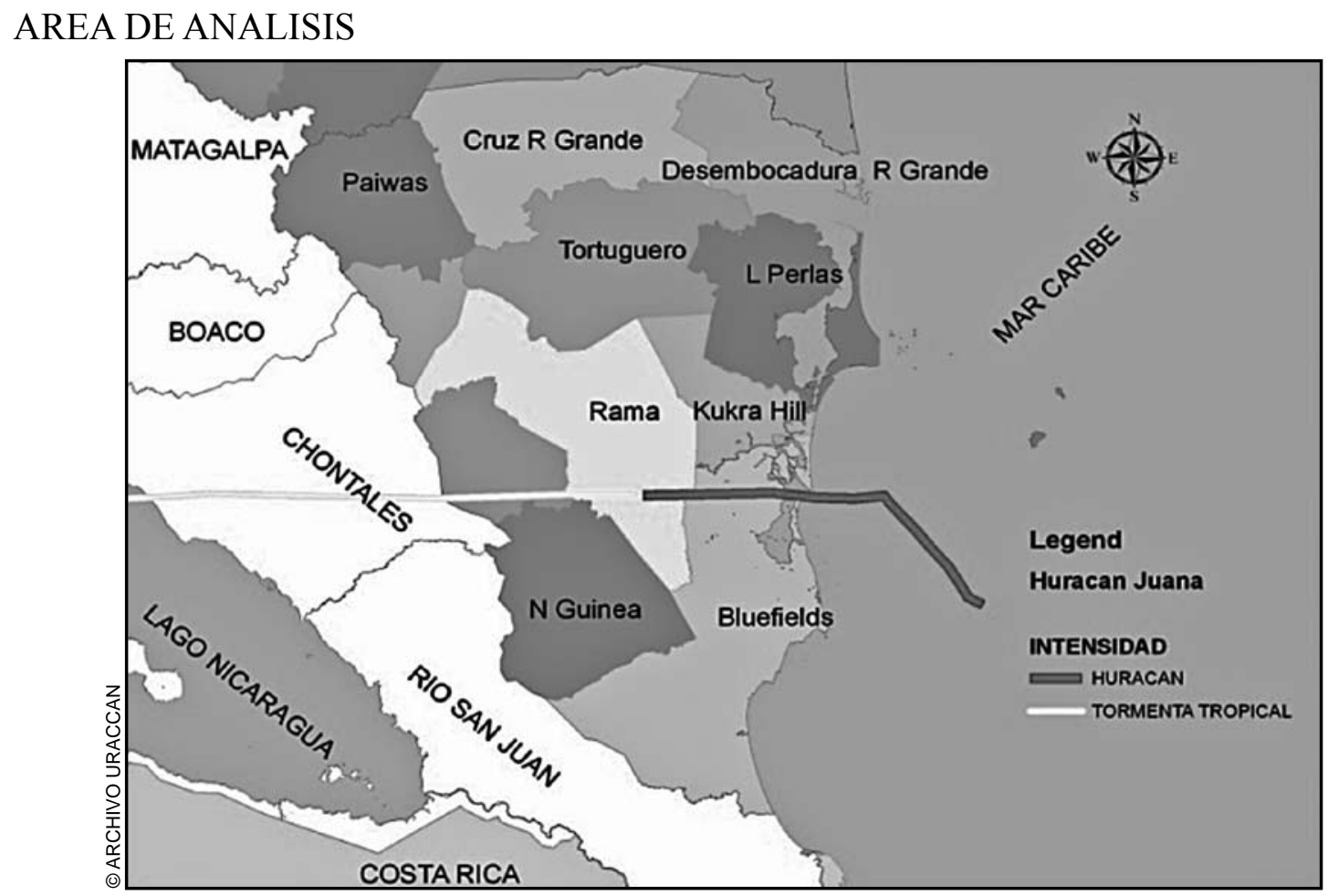

Estos mapas que vienen son ya los modelos de las capas de información. Siguiendo la misma lógica, agropecuario es amarillo, los bosques de pinos abiertos y los bosques de pino cerrado y humedales. Entonces esta es la cobertura que se mostró más o menos en el '83 y ustedes pueden ver, en 1996, la cobertura del 2000 y la cobertura del 2006.

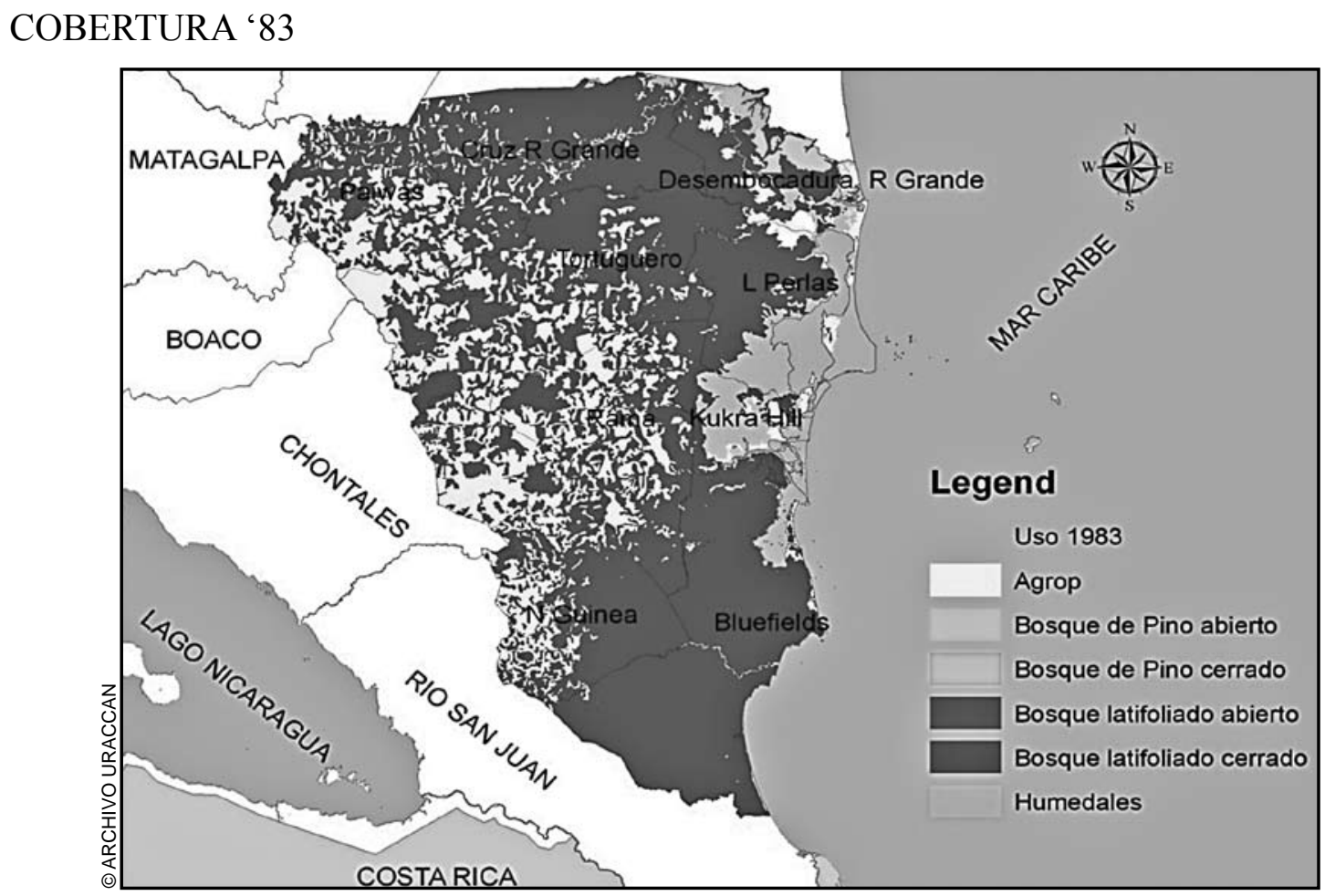




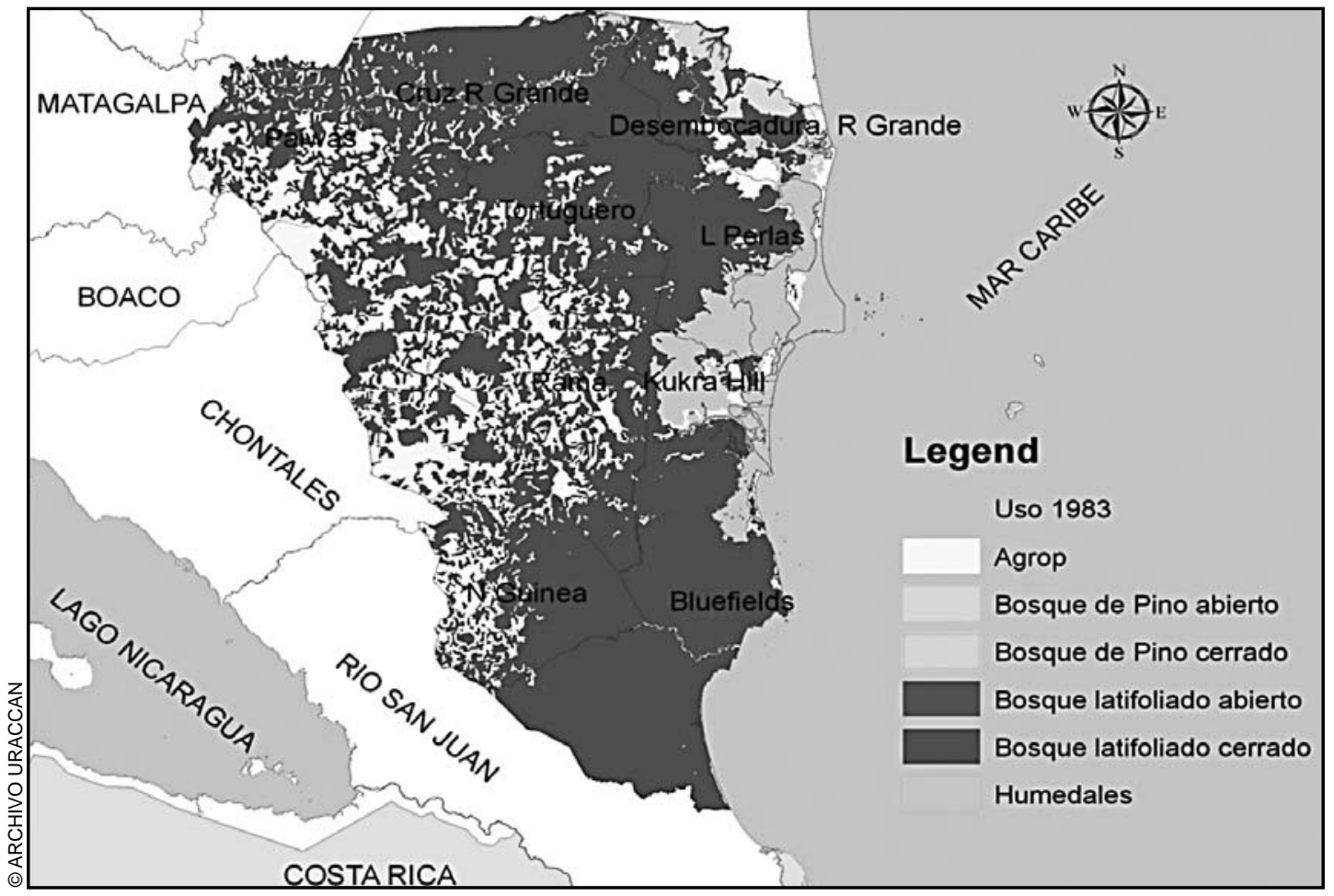

\section{COBERTURA '96}

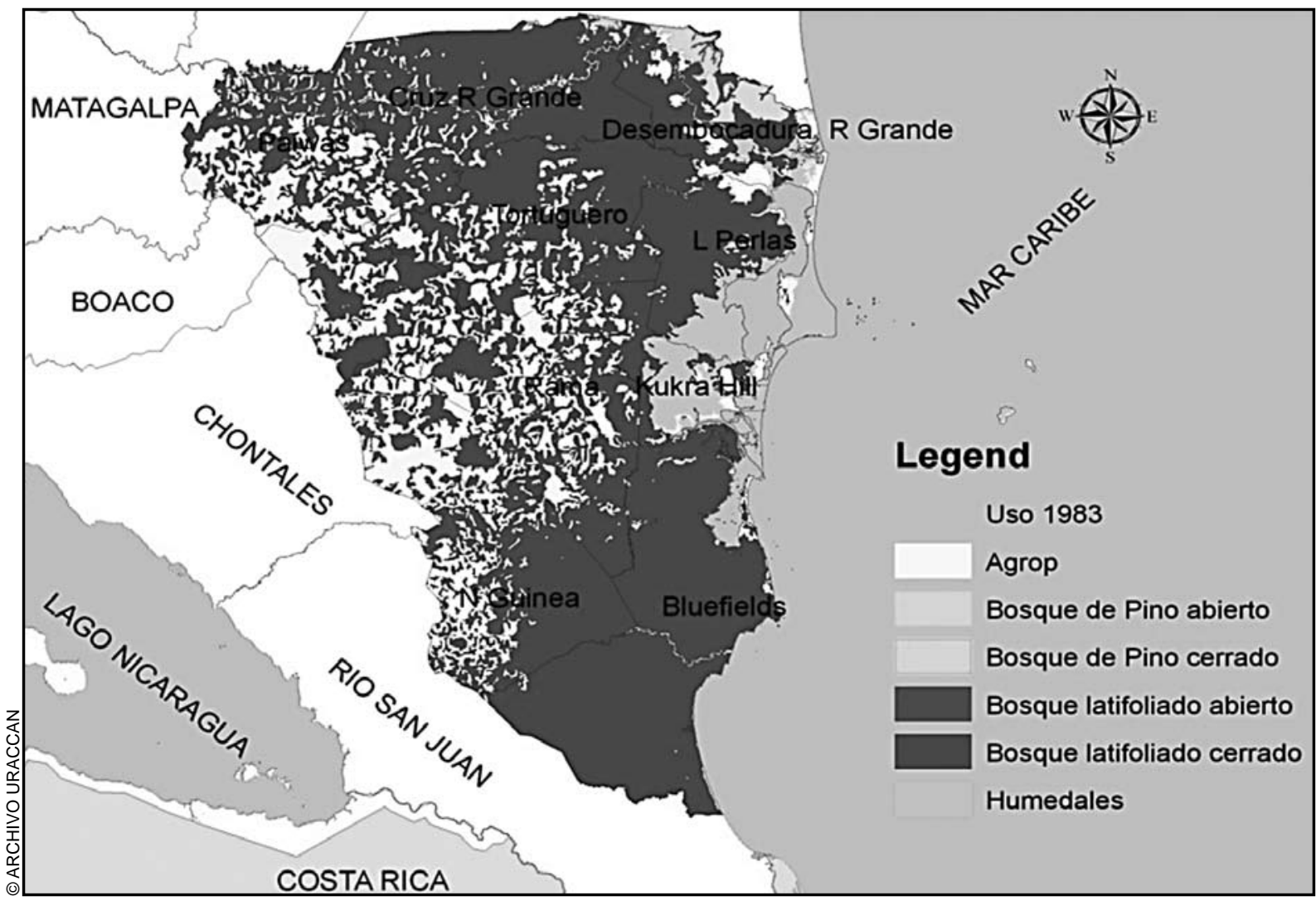


COBERTURA 2000

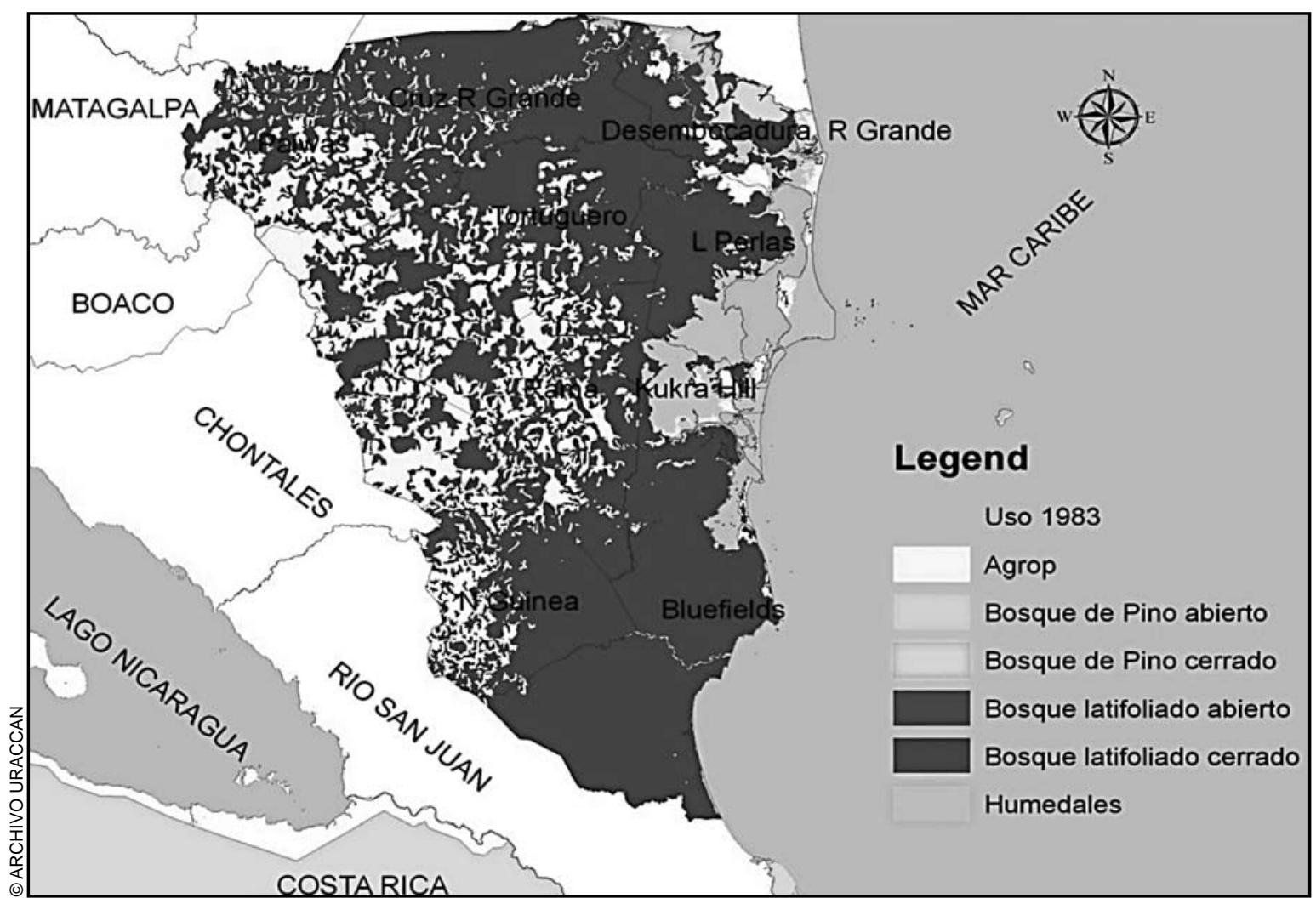

COBERTURA 2006

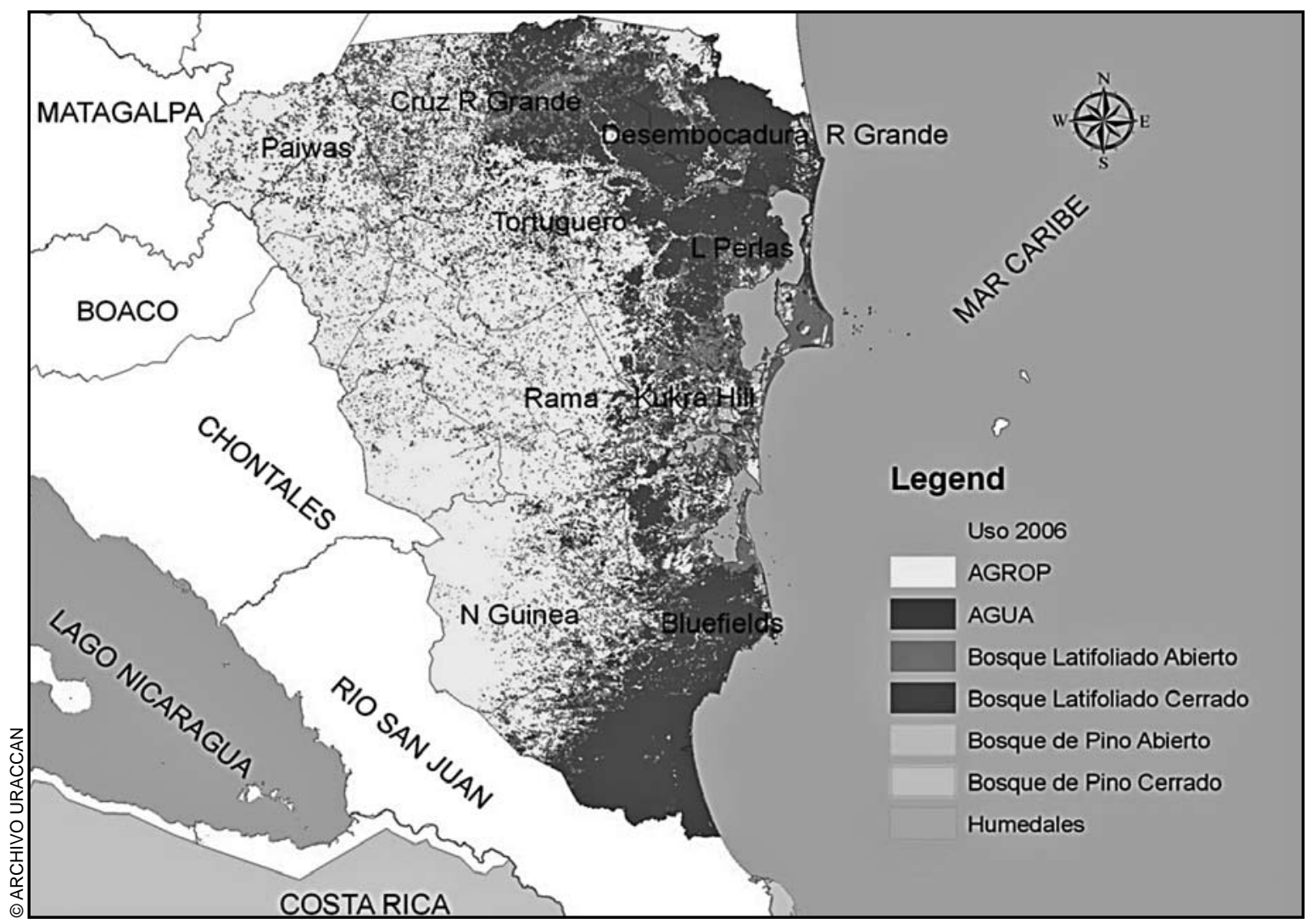


CAMBIOS 83 - 96

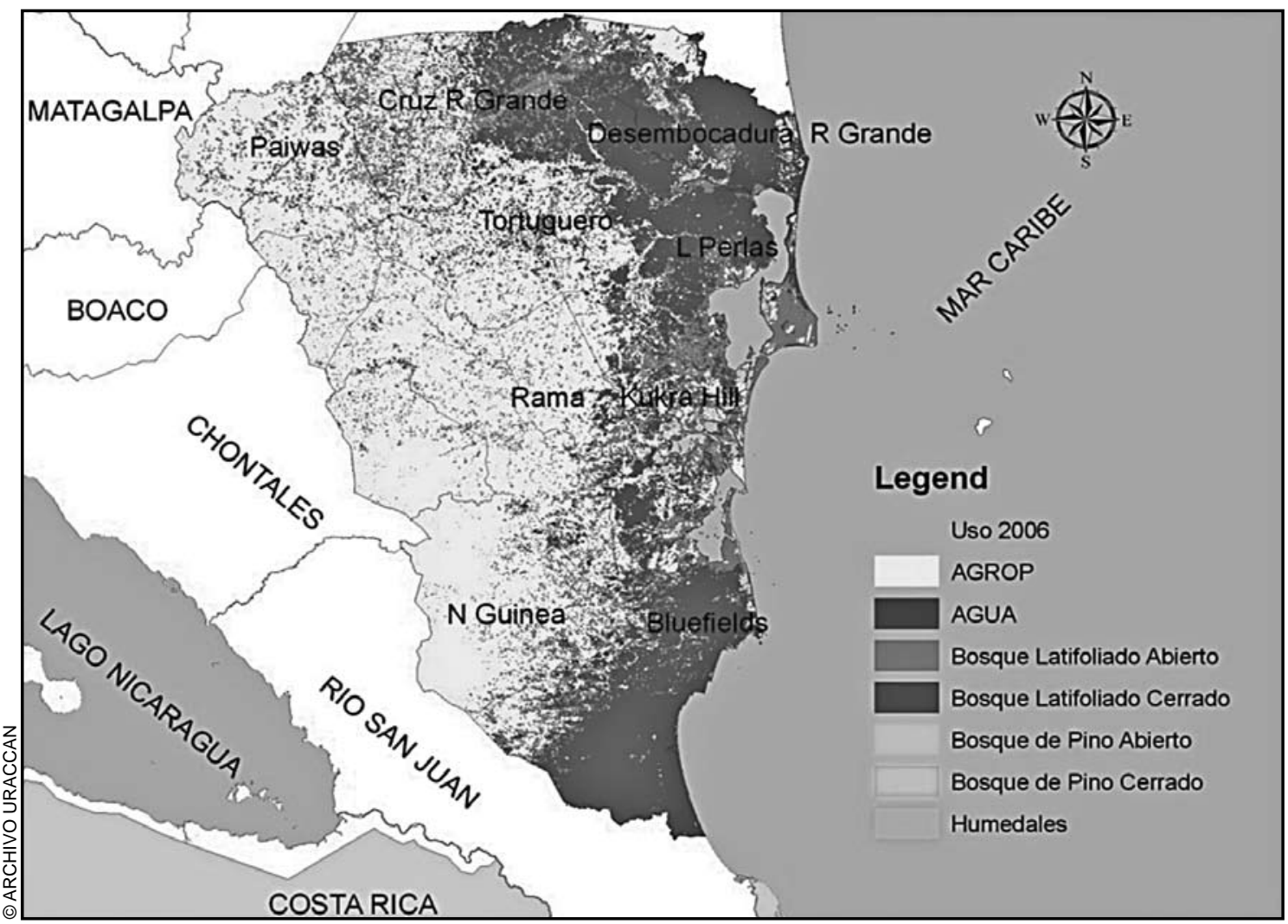

CAMBIOS '96 - 2000

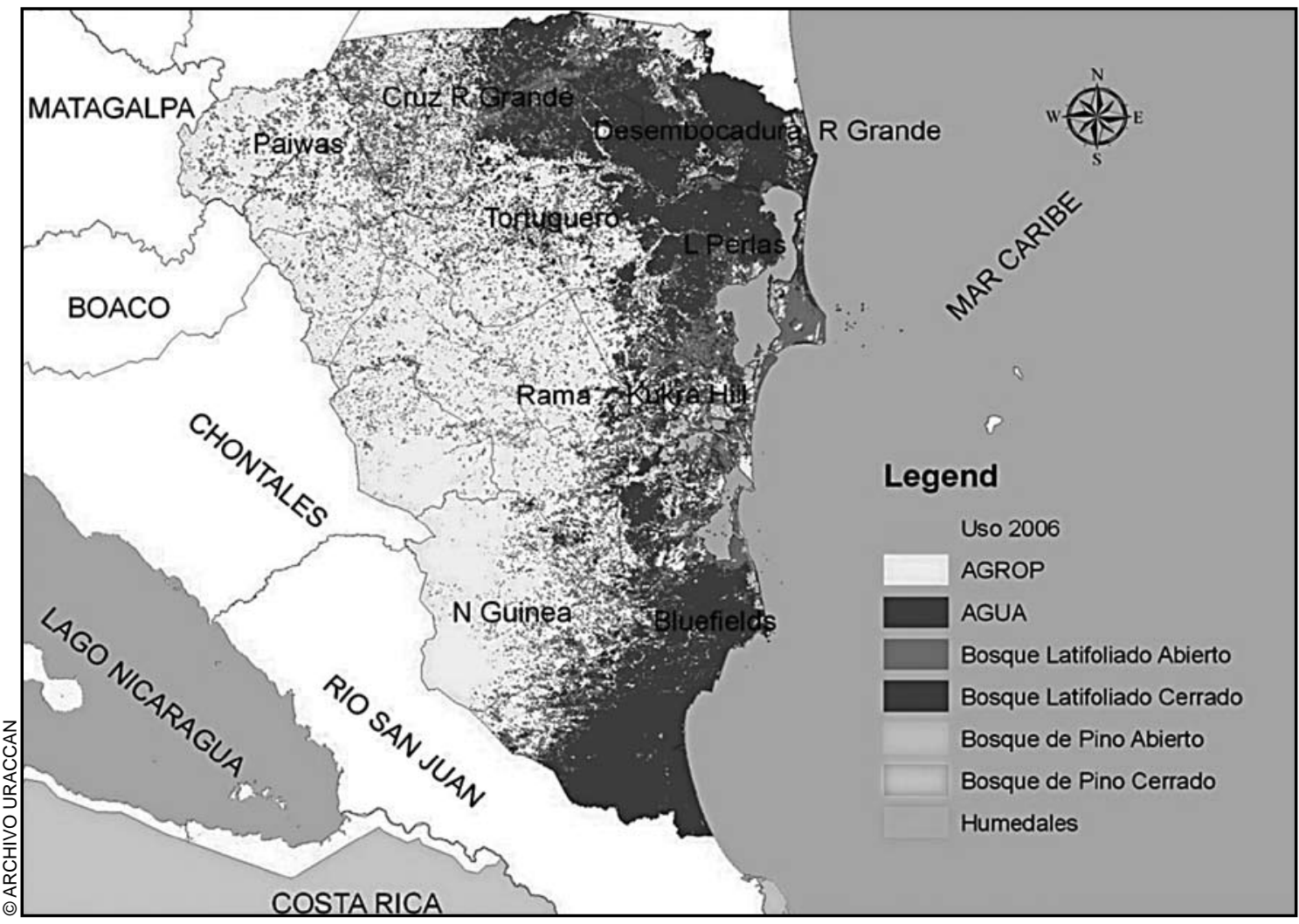




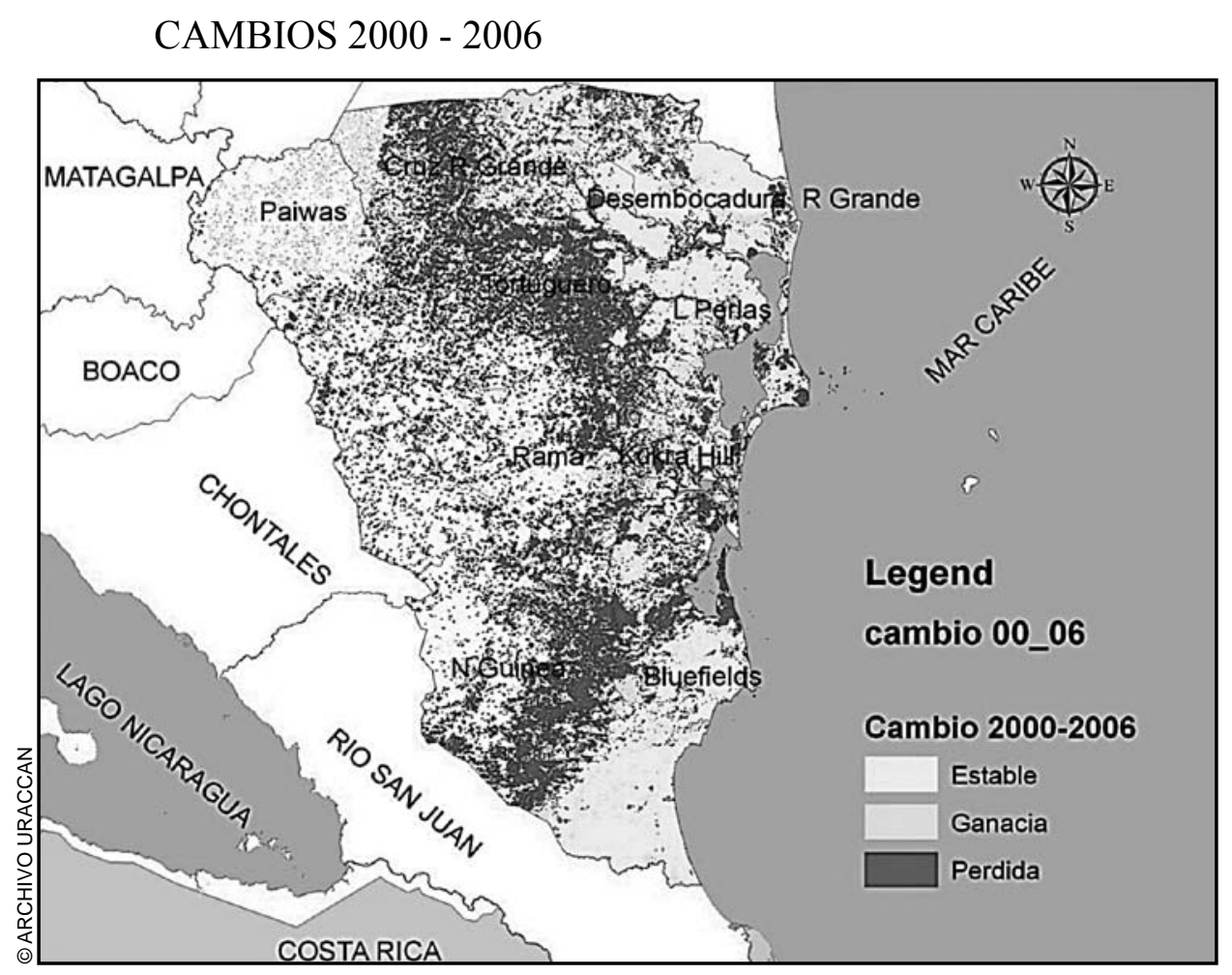

Hay una cierta estabilidad del año 2000 al 2006, pero eso tiene una interpretación. Obviamente hay una estabilidad, porque como aquí ya no hay bosque, entonces ya no hay más pérdida de bosque, pues todo esto se vuelve sistema agropecuario. Entonces se logra detectar que, a pesar de que han pasado veinte años o más del huracán Juana, el cambio del uso del suelo se mantiene producto de la tormenta o fenómeno meteorológico, pero también producto del cambio de uso de suelo que es una de las principales cosas negativas que ocurren cuando pasan fenómenos naturales. Lo que pasa es que esto está ligado al comportamiento social de la gente, es decir, el indígena tiene el bosque, y éste es todo para él, para su usufructo. Pero el campesino tiene otra visión, el bosque para él vuelve a ser un estorbo, por lo tanto, el huracán, al botar el bosque,

El color amarillo es el que representa los sistemas agropecuarios y la medida en que han venido avanzando. Se denotan rápidamente los cambios en el área afectada por el huracán. Aquí todo estaba bien en el '83. Estaba bien representada la cobertura de los bosques latifoliados cerrados. En el '96, coincidiendo con el estudio que presentó la máster Gladys Luna, ya se encuentran los deterioros. Donde pasó el huracán hubo una mayor dimensión del cambio de uso agropecuario en la parte del sector del Rama. Lo interesante de esto es que de manera visual podemos ver en rojo la matriz de cambio, donde es amarillo es estable; ganancia es verde y pérdida es rojo. Entonces, visualmente podemos ver en estos municipios, en el caso de Laguna de Perlas, El Tortuguero y Rama, cómo estaban en 1983 y cómo en el año 1996. Ustedes pueden ver cómo las pérdidas se acentúan justamente en el área en donde impactó el huracán.

Del '96 al 2000, las pérdidas se mantienen en el área en donde impactó el huracán, pero aquí ya hubo una mayor presencia de pérdida de vegetación, ¿A qué es debido? Posiblemente, no es por el huracán, sino que la gente hizo un cambio de uso de suelo. Al no haber bosque la gente metió la agricultura y eso es lo que se logró ver, que se acentuó del año 1996 al 2000. el campesino simplemente hace la transformación. Si volvemos a la matriz de cambio, la estabilidad puede ser producto de que es bosque y sigue siendo bosque.

En conclusión, del resultado de este ensayo algunos resultados tangibles y visibles en los mapas es que existe una mayor susceptibilidad hacia la pérdida del bosque por degradación. Lo pudimos notar claramente. La mayor parte de la pérdida de la cobertura fue hacia la conversión de los sistemas agropecuarios, es decir, el huracán botó el bosque y la gente no trató de que el bosque recuperara, de manera natural, sino que transformó los sitios donde no había bosque en sistema agropecuario.

$\mathrm{Y}$ un tercer asterisco que yo les podría decir es que aparentemente hay una disminución del bosque manglar (lo puse entre paréntesis para monitorear). Eso también nos da otro efecto posible producto de la entrada del huracán. Debido a las desviaciones de las corrientes de los ríos, el bosque manglar de manglar fue afectado ya que éste tiene una alta interrelación con el agua salada. Es bien probable, pues eso ya ha ocurrido en otros lugares con la presencia de este tipo de fenómenos naturales que provocan toda una transformación de los ecosistemas, especialmente lagunares. 